\title{
Environmental Assessment and Dielectric Performances of the Secondary Electrical Insulation in Low Voltage Motors Impregnated by Different Techniques
}

\author{
Manh Quan Nguyen1, Simon Dario', David Malec1, Dominique Mary¹, Jean-Pascal Cambronne1, \\ Damien Prunel2, Julie Orgelet ${ }^{2}$
}

${ }^{1}$ LAPLACE, Université de Toulouse, CNRS, INPT, UPS, Toulouse, France

${ }^{2}$ Bureau Véritas, Moirans, France

Email: malec@laplace.univ-tlse.fr

How to cite this paper: Nguyen, M.Q., Dario, S., Malec, D., Mary, D., Cambronne, J.-P., Prunel, D. and Orgelet, J. (2017) Environmental Assessment and Dielectric Performances of the Secondary Electrical Insulation in Low Voltage Motors Impregnated by Different Techniques. Engineering, 9, 860-873.

https://doi.org/10.4236/eng.2017.910051

Received: June 14, 2017

Accepted: October 13, 2017

Published: October 16, 2017

Copyright $\odot 2017$ by authors and Scientific Research Publishing Inc. This work is licensed under the Creative Commons Attribution International License (CC BY 4.0).

http://creativecommons.org/licenses/by/4.0/

\begin{abstract}
A recent technique, using to potentially replace the conventional impregnating one in low voltage electric motors, has been studied in this communication. The conventional technique that uses both primary and secondary insulations; i.e.: enamel and varnish, has been compared to this recent technique which only uses one component, i.e.: self-bonding wires. Self-bonding wires polymerization is very quick compared to that of the conventional technique. Environmental impact and both dielectric and mechanical properties of these two techniques have been estimated and compared. The goal is to estimate if this recent technique has not only a better environmental footprint but also good technical properties. The dielectric properties that have been measured are the dielectric strength and the lifetime under pulse voltage while mechanical consists in measuring the bonding strength that is crucial for impregnation. For that purpose, a Life Cycle Assessment (LCA) that can simultaneously evaluate numerous impacts on ground, water and air, has been performed. The results show clearly that the recent technique significantly reduces the environmental footprint. Both mechanical and dielectric properties are then compared and analyzed.
\end{abstract}

\section{Keywords}

Electrical Motor, Enameled Wire, Self-Bonding Wire, Impregnation Technique, Dielectric Performance, Environmental Impact 


\section{Introduction}

The windings of electric motors (stators and rotors) are obtained by using enameled copper wires and a layer of organic insulating varnish. The role of this varnish is to protect the winding against moisture and pollution and to fix it on the magnetic core to avoid any friction that may cause wire damage, leading to its deielectric breakdown. Traditionally, these coils are impregnated with an impregnating varnish cured at $120^{\circ} \mathrm{C}$ to $200^{\circ} \mathrm{C}$ (depending on the type of varnish) for several hours to reach its full polymerization. Energetically, this coating method is expensive and generates waste: varnish residues, rags, ... In addition, the impregnating varnish has a complex formulation including a solvent mixture, a pre-polymer, cross-linking agents and multiple additives. Depending on the chemical nature, it contains between $18 \%$ and $40 \%$ dry extracts (useful portion), the rest being the solvents or volatile organic compounds (VOCs) which maybe a risk for both human health and environment (N-methyl pyrrolidone, aliphatic and aromatic solvents such as naphtha, xylene, toluene, etc). Thus, there is about $60 \%$ of used product that evaporates and must be "normally" treated which does not preclude that a more or less significant part can be released directly into the air [1]. Moreover, the combustion of these solvents naturally emits a lot of $\mathrm{CO}_{2}$ of which we know the environmental impact. For these reasons, both economic and ecological, an alternative solution is to wrap enameledwirespre-impregnated with varnish to form a coil. Instead of bringing the heat convection and radiation during the polymerization phase, the wires are subjected to an electric current in a given short period. However, such techniques are a challenge to meet the needs of insulation systems. To estimate the benefits and limitations of this alternative technique, different experiences will be detailed and analyzed in this communication. Two types of twisted pair of individually impregnated enameled wires (classical, self-bonding) were successively tested. First, the dielectric properties such as dielectric strength (50 $\mathrm{Hz}$ sine voltage-room temperature), the lifetime (square voltage $1.5 \mathrm{kV} / 15 \mathrm{kHz}$ $-55^{\circ} \mathrm{C}$ to $180^{\circ} \mathrm{C}$ ) and the polarization index (DC $1 \mathrm{kV}$, room temperature to $180^{\circ} \mathrm{C}$ ) were evaluated. Finally, relating to environmental impacts, a study based on the principle of analyzing the winding impregnationstep will be presented.

Since the last past ten years, some primary and secondary insulation products contain nanoparticles in order to resist to partial discharges occurrence. These "corona-resistant" products are chosen when machines are fed by inverters because of the risk of strong overvoltage appearance. But currently the nanoparticles toxicology is not yet integrated in environmental databases. That is the reason why this study only concerns classical materials, i.e.: polymer without nano-fillers.

\section{Electrical Insulation Systems (EIS) of Low Voltage Motors}

As in most electrical assemblies with coils, proper operation of a motor depends greatly on the quality of its Electrical InsulationSystem (EIS). For low-voltage 


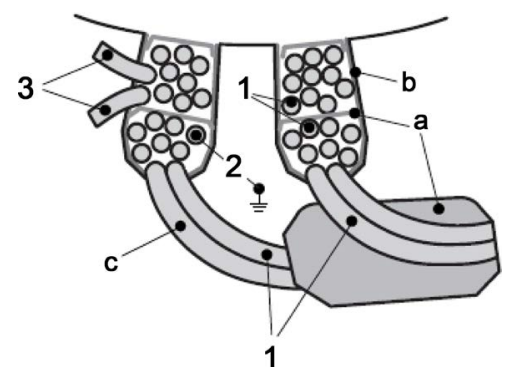

Figure 1. Low voltage Electrical Insulation System: between phases (a), slot insulation (b) and inter-turn insulation (c) [2].

motors, this EISincludes a large number of insulating materials:firstly between thewires constituting each winding and secondly between the coil and the magnetic core of the motor. Figure 1 shows a cross section of a low voltagestator that identifies the different types of insulation. Depending on the desired insulation between phases (item a) between coil and core (item b) and between turns (item 3), the material used to achieve it will be different because the environment in which it is located (temperature, geometry, voltage) will itself be different.

\subsection{Inter-Turn Insulation}

Low voltage motors have usually random-round coils rathen thenform-round coils (used in high voltage motors). The insulation between the windings is ensured by polymer resins coatingwires. For LV motors, its thickness is approximatively a few tens micrometers. Industrially, enameled wires consist of several enameling varnish layers of the same or different nature which are necessary for the various functions required: adhesion to copper wire, electric strength, temperature resistance, adhesion of varnishes coating.

- There are six kinds of polymers used in primary insulation (having different thermal index) [3]:

- polyvinyls used at low temperatures $\left(<120^{\circ} \mathrm{C}\right)$.

- polyurethanes particularly suitable for the coating of fine wires and therefore often used for low power applications (electronics, appliances, ...)- thermal index $155^{\circ} \mathrm{C}$.

- polyester-imide results from the association of imide groups on polyester structures. They achieve operating temperatures of $180^{\circ} \mathrm{C}$.

- polyesters with THEIC (Tri-2Hydroxy-Ethyl-isoCyanurate) having interesting thermal and mechanical characteristics; they allow high operating temperatures $\left(200^{\circ} \mathrm{C}\right)$.

- polyester-imide with THEIC essentially characterized by their thermal performance $\left(200^{\circ} \mathrm{C}\right)$ and high chemical resistance.

- polyamide-imides of which thermal class is $220^{\circ} \mathrm{C}$. Apart from their good thermal class, they are characterized by their resistance to many chemical agents and their good sliding properties.

- polyimides which are the materials with the most efficient temperature performance (up to $240^{\circ} \mathrm{C}$ ). They also exhibit excellent resistance to thermal 
shoc. Nevertheless, thermal and electrical properties of this material are strongly impacted by the moisture.

The choice of an enameled wire is based on the heat class of the machine and the application. A particular attention should be paid to the selection of enameled wire for motors fed by PWM inverter. Indeed, the use of such power supply can generate surge two to three times higher than the rated voltage of the machine. These surges will induceat least partial discharges occurrence (PD) and at worst a dielectric breakdown of the winding electrical insulation. To ensure better resistance to partial discharges, one possible solution is to fillthe polymer matrix with inorganic particles $\left(\mathrm{Al}_{2} \mathrm{O}_{3}, \mathrm{TiO}_{2}, \mathrm{SiO}_{2}, \mathrm{ZnO}\right.$...) to obtain "coronaresistant" wires [4] [5].

\subsection{Slot Insulation}

Unlike the insulation between turns, slot base insulation (see Figure 2) is subjected to electrical stresses but at a lower temperature due to the heat dissipation through the metal ground. Its role is to insulate the winding from the ground (magnet core).

For that purpose, different insulating materials are used. They can be classified into three main types: discrete elements, flexible laminates and coated materials:

- discrete elements are simple materials, usually papers (kraft, inorganic, leatheroid or aramid) or films (polyester, polyimide). They are especially selected for this type of insulation due to their excellent electrical and mechanical properties

- laminates are flexible insulating associated in several layers by laminating in order to obtain materials having a combination ofhigh performance properties. Combinations of complex, two or three layers, are multiple. Examples commonly encountered are: KMK and KM, RM and CMAs, MD and DMD, NM and NMN and NKN where R: rag paper, M: polyester film (PET), D: polyester fleece, $\mathrm{N}$ :aramid paper and K: polyimide film.

- coated materials are composed of a resin coating various substrates to improve their dielectric properties. The substrates are typically fabrics, films or aramid papers. The coatings are polyester, silicone or epoxy resins. This

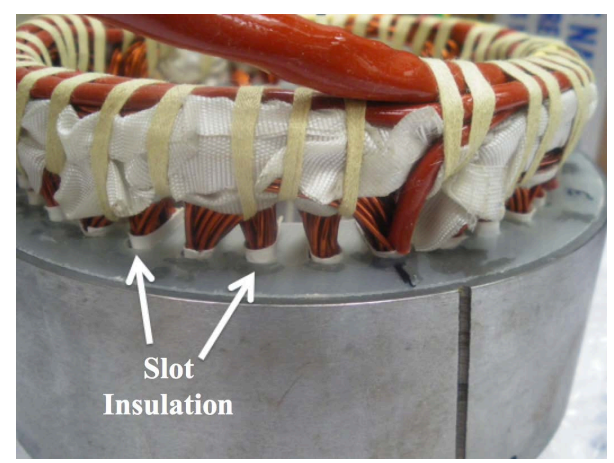

Figure 2. Slot insulation of a low voltage motor. 
type of material is commonly used for insulation between phases as well.

\subsection{Inter-Phases Insulation}

The role of the electrical insulation between phases is to avoid direct contact between different phases (see Figure 3). Such insulation must be electrically good, mechanically strong and thermally compatible with the other components of the insulation system. For this purpose, the materials used here are the same as those used in the slot base insulation.

\section{Impregnating Varnish}

Impregnating varnishes are deposited on the windings already inserted into the slots. The impregnation step consists in covering the winding with a varnish mixed in a solution containinga solvent or a reactive monomer. Its aim is to "weld" enamelled wires together. By infiltrating into the interstices within the coils, the coating further the dielectric properties of the insulation. It heals some defects (cracks in the enamel, micro-tears in the sheets, ...). The role of this varnish is particularbecause despite of his good electrical properties, electrical insulation is not its primary role (unless specific application where insulation is strongly used [6]). It is rather a role of mechanical cohesion of the coil/stator cage assembly that will insure. The aim is to block the winding so that it is more resistant to the centrifugal force and vibration. The wiresare carrying current with different amplitudes and sense, that's why the forces acting on the wires by action of these currents must also be contained. In addition, the impregnating varnish also facilitates the evacuation of the heat produced by Joule effect in the wire and prevents the penetration of moisture, dust, dirt and aggressive chemicals that can reduce the enamelled wire lifetime.Varnishes commonly used are based on polyesters, epoxides or polyester-imides:

- varnishes based on polyesters usually consist of a monomer or a solvent. They are extremely reactive and easy to use. However, they are weak in mechanical strength (friability) at high temperature.

- epoxy-based varnishes not only have excellent mechanical and chemical resistance, but also a relatively high viscosity. Their thermal properties are comparable with those of high temperature polyester-imides.

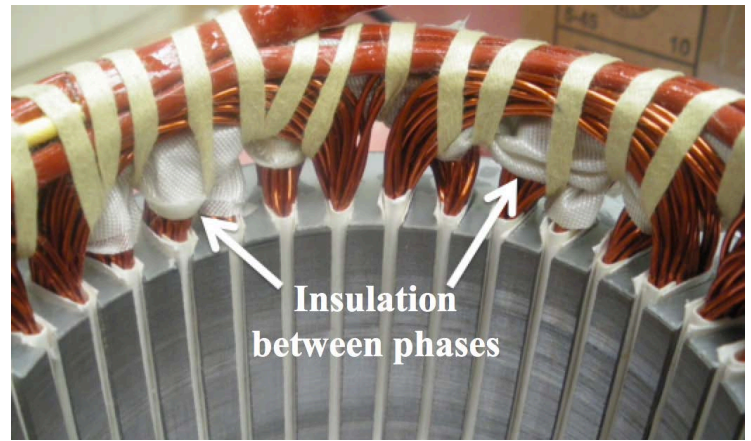

Figure 3. End winding interphases insulation of a low voltage motor. 
- polyester-imides-based varnishes are roughly similar to polyester-based varnishes, but with improved dielectric properties at high temperatures. They also have an excellent compatibility with enamels.

The main constraints the impregnation varnishes have to withstand are the compatibility with enamel during its implementation as well asmechanical, environmental and thermal stresses during system life.

\section{Different Coating Techniques}

The various coating techniques are used depending on the implementation equipment, the type and the quantity of parts to be treated, and the desired result. They can be classified into two different categories: standard and alternative technique.

\subsection{Conventional Technique}

This technique consists in immersing the motor in a varnish. Then it is allowed to drain before passingthrough the so-called "polymerization" oven (120 to $200^{\circ} \mathrm{C}$ in several hours, depending on the varnish type). The aim of the polymerization is to evaporate the solvent and or to achieve crosslinking. The impregnation of the varnish is commonly done:

- drip or sprinkling. In this impregnation technique, the stator (or rotor) wound is placed with its axis vertically or slightly inclined. It is brought to a temperature of the order of $80^{\circ} \mathrm{C}$ to $100^{\circ} \mathrm{C}$. The varnish is then poured over the winding heads while the machine is running slowly. In contact with the hot coil, the varnish becomes fluid and penetrates into theconductors bundle, the slots and the winding heads

- dip method, possibly with vacuum and/or pressure assistance. This process requires inexpensivefacilities. The coiled machine must be dried in an oven, and then cooled to $40^{\circ} \mathrm{C}$ or $50^{\circ} \mathrm{C}$. At this temperature, moisture absorption is avoided and the varnish in contact with the coils is thinned at the time of immersion in the tank or dip tank. A variant allows applying the dipimpregnation on rotors by rotation to the surface of a tank.

- in a vacuum and pressure autoclave system. This technique is called "Vacuum, Pressure Impregantion" (VPI). This technique allows better penetration by prior elimination of occluded air and moisture in the insulation. The impregnation stand essentially comprises an autoclave, a varnish tank, one or two vacuum pumps and their associated valves, the piping and the control equipment. A pre-drying stage is used to remove most of the moisture. The immersing machine was then subjected to vacuum in the autoclave to remove the last traces of moisture and especially the air. After a sufficient time (a few hours), the vacuum pump continuing to operate, the varnish is injected into the autoclave to immerse the machine. After immersion, the autoclave is pressurized with air or nitrogen, which further facilitates penetration of the varnish. 


\subsection{Alternative Technique}

The objective of this technique is to replace the traditional windings impregnation carried out by long processes (several hours), emitting pollution (VOC) and expensive (high cost of heating energy) by a faster process with low pollution and cheaper as well. This alternative technique consists in using self-bonding wires instead of conventional enameled ones. A self-bonding wire is a classic enameled wire with an adhesive enamel overcoat. Heating or using solvent may be used to obtain the adhesive enameled wires polymerization. Once activated, the adhesive layer polymerizes the winding turn by turn to join them together. In this alternative technique, different processes may perform the polymerization:

- by baking in an oven (between 5 and $30 \mathrm{~min}$ from $130^{\circ} \mathrm{C}$ to $220^{\circ} \mathrm{C}$ ).

- by blowing hot air $\left(140^{\circ} \mathrm{C}\right.$ to $\left.230^{\circ} \mathrm{C}\right)$.

- by induction: magnetic circuit constituting the inductor will heat the coil.

- by using a current flow in the coil. The coil is fed by a current source, and will heat by Joule's effect.

The last of these solutions is the lowest energy-consumer and has been consequently studied in our work. The amount of energy to bring to the self-bonding wire $\left(\mathrm{Ri}^{2} . \Delta \mathrm{t}\right)$ to achieve a perfect bonding between contiguous turns without damaging the thermo-adhesive layer is fixed by the manufacturer. This amount of needed energy is consequently known, and considering a given current i supplied by the current source, the application time $\Delta t$ of this current can then be calculated.

\section{Impact of the Coating Technique on the Dielectric Properties}

\subsection{Samples Conditioning}

Samples used in this study are twisted pairs (see Figure 4) built from enameled copper wire following the standard NEMA MW 1000 [7]. As part of this study, two types of enameled wires (classical, self-bonding) were used. To be comparable, we have trade enameledwires that consist of the same insulating varnish. Their typical values are summarized in Table 1 .

After the preparation of twisted pairs, these are "glued" with both techniques. Twisted pair performed by using conventional enameled wires were impregnated with the VPI techniquewith a varnish based on polyamide-imide (PAI-Rhodelftal) before baking in the oven (see Figure 5 for the baking cycle).

Twisted pairs made with self-bonding wires in this study were thus polymerized by current flow (current value and application time extracted from manufacturer data).

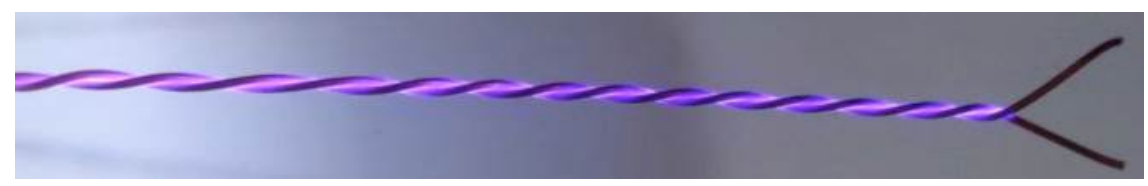

Figure 4. Twisted-pairs used as samples (here under HV pulse voltage generating corona). 
Table 1. Enameled wires characteristics.

\begin{tabular}{ccc}
\hline & Conventional wires & Self-bonding wires \\
\hline Copper diameter & $0.5 \mathrm{~mm}$ & $0.5 \mathrm{~mm}$ \\
Grade & 2 & 2 \\
First enamel layers & Polyester-imide (THEIC) & Polyester-imide (THEIC) \\
Second enamel layers & Polyamide-imide & Polyamide-imide \\
Self bonding coat & --- & Polyamide aromatique \\
Thermal index & $210^{\circ} \mathrm{C}$ & $210^{\circ} \mathrm{C}$ \\
Thermo-plasticity & $340^{\circ} \mathrm{C}$ & $\geq 340^{\circ} \mathrm{C}$ \\
Flexibility & $10 \%+1 \mathrm{diam}$. & $10 \%+1$ diam. \\
Elongation max. & $35 \%$ & $35 \%$ \\
\hline
\end{tabular}

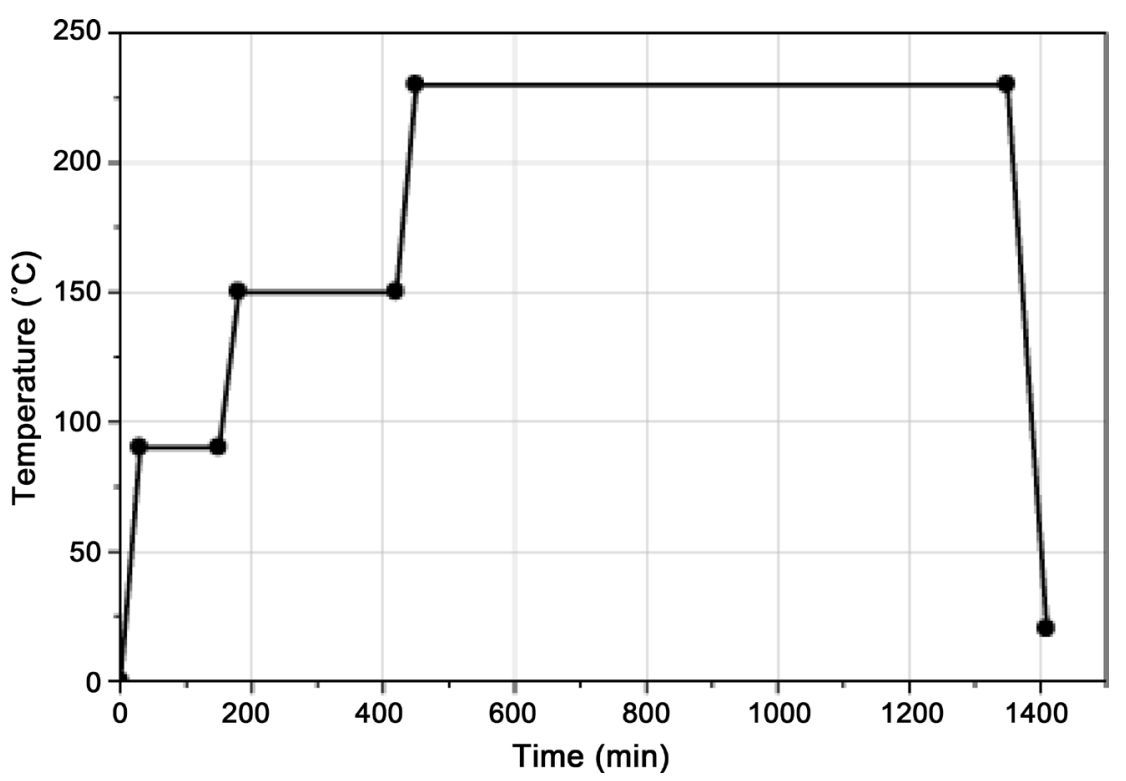

Figure 5. Varnish thermal cycle.

\subsection{Experimental Evaluation of Electrical Properties}

Measuring the dielectric strength is a destructive test. This test consists in increasing the $50 \mathrm{~Hz}$ sine voltage until the detection of a current flow through the sample higher than $10 \mathrm{~mA}$ (voltage rising rate: $500 \mathrm{~V} / \mathrm{s}$ ). During the experiment, the samples were immersed in an insulating liquid in order to avoid surface discharge and thus measure the "intrinsic" breakdown electric field. The experimental protocol is described in the standard ASTM D 149-97 [8].

The lifetime tests were estimated by applying a square voltage (bipolar $+/-1.5$ $\mathrm{kV}, 15 \mathrm{kHz})$ at different temperatures $\left(-55^{\circ} \mathrm{C}, 20^{\circ} \mathrm{C}, 180^{\circ} \mathrm{C}\right)$. To assess the ability of the samples to resist a surface discharge activity, these tests were performed in air. The data presented in the following section were achieved by using Weibull statistical processing with two parameters.

The adhesive strength ofthe varnish (classical or thermo-adhesive impregnation) is generally assessed by measurement described below [9]. This measurement is 
performed on a contiguous turns solenoid manufactured using an enameled wire (normal or self-bonding). For conventional wire, impregnation (identical to that of the motor) is performed to maintain the windings to each other; for self-bonding wire, it is heated in the same manner as in the motor winding. A pressure is applied to the center of the solenoid supported at both ends (Figure 6). When the impregnating varnish (or the self-bondingwire overlay) give away, the applied pressure value is recorded, it is the force required to break the bond between the turns provided by the varnish (or self-bonding layer).

\subsection{Experimental Results}

The experimental results have been compiled in the following curves (Figures 7-9).

As shown by the obtained results, the twisted pairs carried out using self-bonding wires and impregnated with the alternative technique exhibit a higher breakdown voltage than those obtained with the conventional technique. This effect can be attributed to the self-bonding polymeric overlay of highly insulating properties.

However, the lifetime under partial discharges regime (PWM power supply) is lower with the self-bonding wires. This can be explained by the fact that the discharges occur in the open cavities located between wires. Inself-bonding wires
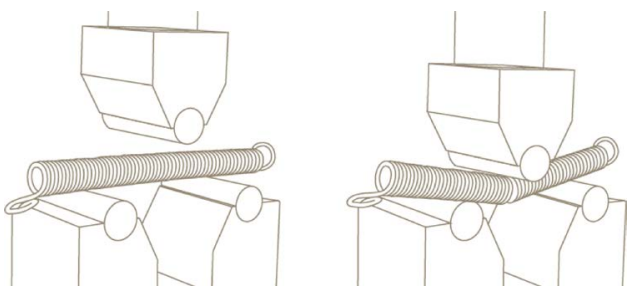

Figure 6. Bonding strength test.

\section{Breakdown voltage $(\mathrm{kV})$}

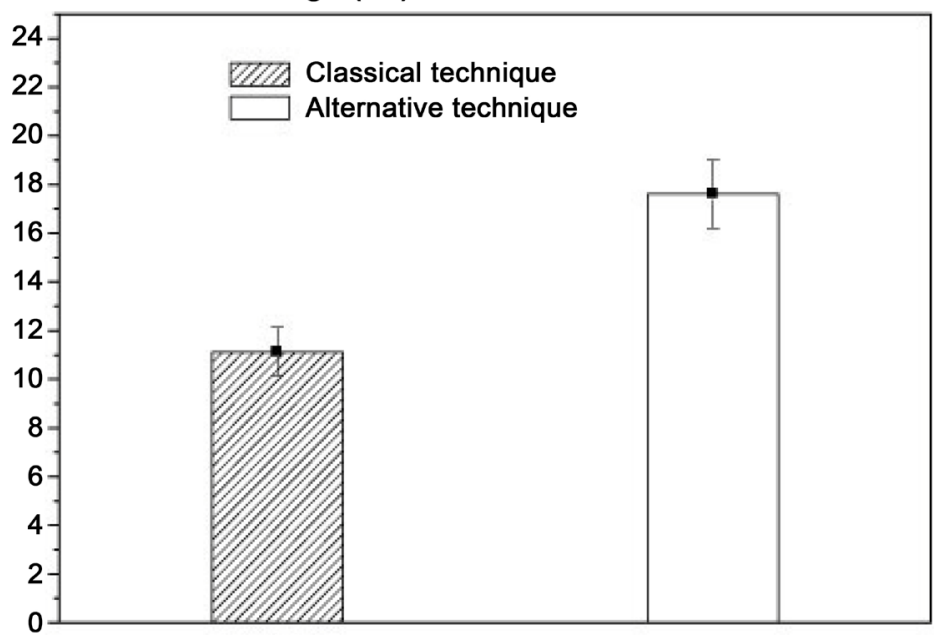

Figure 7. Dielectric strength of twisted pairs impregnated by different techniques(AC sine $50 \mathrm{~Hz}$, Room temperature, Weibull'sstatistical treatment (8 samples/technique), 90\% confidence bounds). 


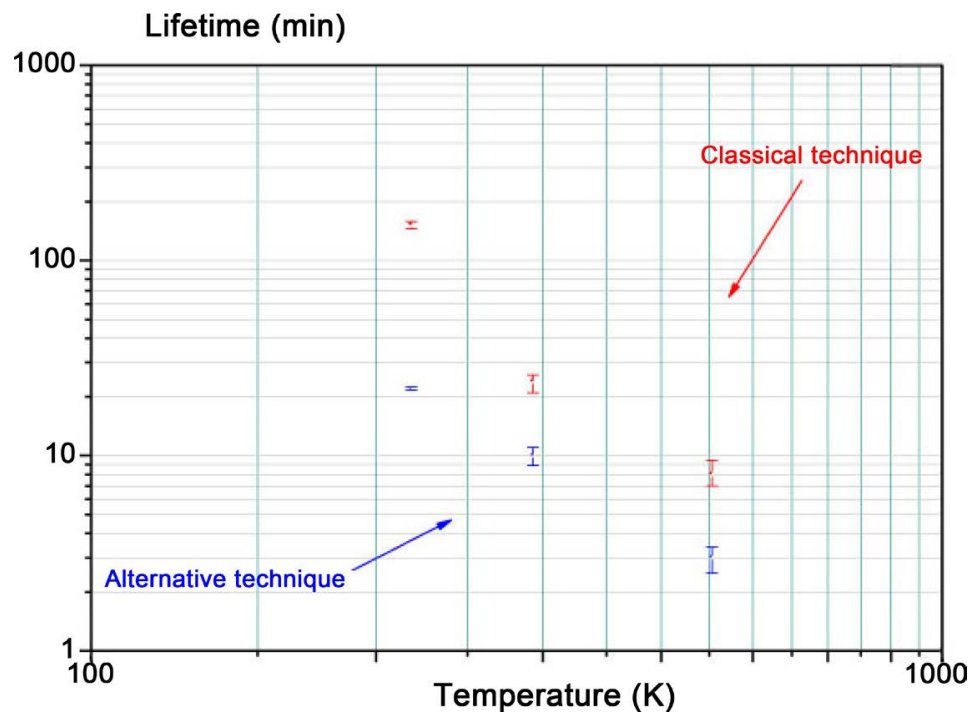

Figure 8. Lifetime of twisted pairs impregnated by different techniques-Bipolar pulses +/- $1.5 \mathrm{kV}, 15 \mathrm{kHz}$, Room temperature; Weibull's statistical treatment (8 samples/ technique); $90 \%$ confidence bounds.

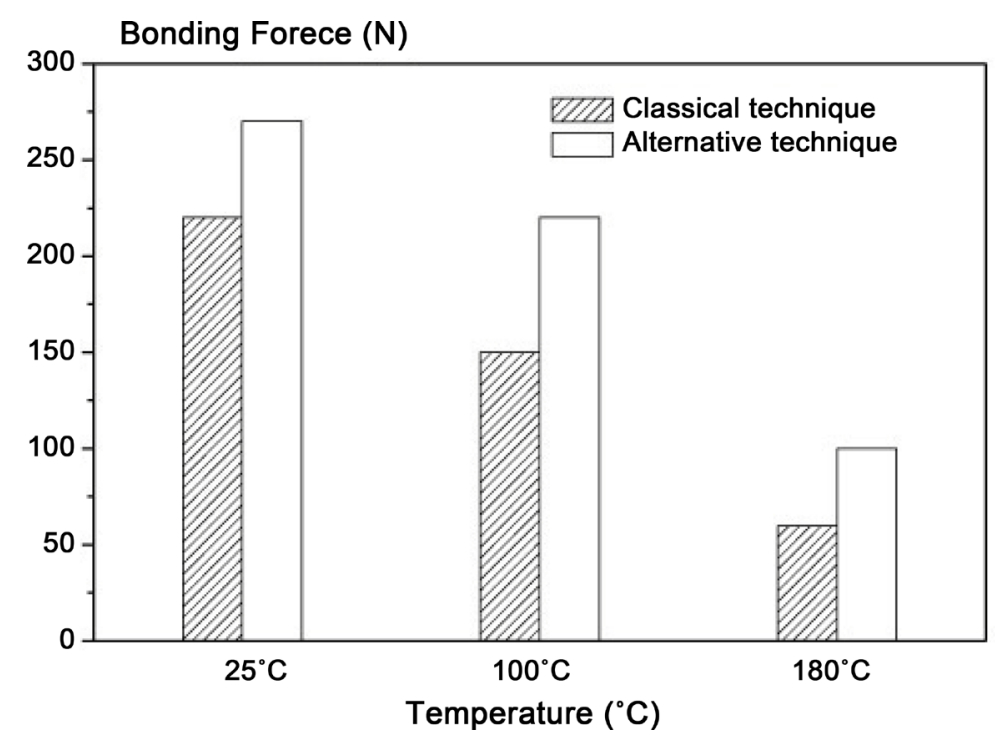

Figure 9. Bonding strength versus temperature for solenoids impregnated by different techniques.

case,a lack of varnish near the discharge location will destroy much faster enamel and lead to a lower lifetime. Consequently, the self-bonding wiresarenot recommended to motor fed by invertersbecause of this risk of partial discharges occurrence.

The bonding strength measurementsthat are given in Figure 9 clearly indicate that the "cohesion" of the coil is improved with the use of self-bondingwires. This improved cohesion, enhanced in a coil whereall thewires touch in 3 dimensions, is due to the fact that the self-bonding varnish is present everywhere on the wire. Indeed, in the conventional impregnation technique, the presence of varnish to all points of contact between turns is not guaranteed and depends 
very much on the type of varnish used, on the impregnation method and on the coil morphology.

\section{Comparison of the Life Cycle Analysys (LCA) of the Two Impregnation Techniques}

\subsection{Procedure}

This study is based on the principle of the life-cycleanalysis applied to both impregnation techniques. The objective is to determine which technical solution has the lowest environmental impact. The modeling of these two methods was performed from the CODDE database (11.0) of EIME software (version 4.0). The information collected is based on the impregnation of 100 windings of low-voltage motors (a few $\mathrm{kW}$ machines). To model the two methods we have considered:

- the production of consumables related processes (welding, thinner, rags, gloves, ...).

- the supply of consumables.

- water and energy consumption.

- emissions into water.

- emissions into air.

- wastes and manufacturing rejects production.

- wastes and manufacturing rejects treatment.

Only the processes were analyzed.The impact of the enameled wire (two types of wires) and impregnating varnish manufacturing are excluded from this study. These methods can be summarized by:

- Conventional and varnished enameled wires: winding, motor preheating, impregnation tank under vacuum, impregnating, emptying and draining, excess varnish removal, drying, cooling, cleaning equipment.

- Self-bonding process: winding, current flow through heating.

Both processes produce waste (soiled rags, gloves, hose reels, ...) transported to the sorting center. This waste is then either recycled or incinerated. In all cases this revaluation has not been taken into account in modeling because the impacts avoided through recycling are allocated to the product that will integrate these recycled elements; the impact of recycling are in fact taken into account in the step of manufacturing equipment.

\subsection{Environmental Indicators}

The software used in this sudy (EIME) allows the environmental impact on 11 indicators:

- WD (Water Depletion): water consumption.

- ED (Energy Depletion): primary energy consumption.

- HWP (Hazardous Waste Production): hazardous waste.

- AA: Air Acidification.

- AT: Air Toxicity.

- GWP (Global Warming Potential): production of greenhouse gases. 
- OD (Ozone Depletion): reduction of the ozone layer.

- POC: Photochemical Ozone Creation.

- RMD (Raw Material Depletion): consumption of raw materials or depletion of natural resources.

- WE: Water Eutrophication.

- WT: Water Toxicity.

The EIME methodology integrates a weight unity for each indicator, so consider indicators as a whole, such as critical as each other. An eco-design approach requires, wherever possible, to reduce all. Each company has the ability, depending on the region or its industry, to favor certain indicators.

\subsection{Processes Analysis}

The two figures below (Figure 10 and Figure 11) represent the environmental impact according to the main steps of both winding imprgantion processes.

The $\mathrm{CO}_{2}$ footprints of the two processes are given in Table 2 (data for only one motor).

In Table 3 are summarized the results from the modeling of both processes. The percentages are used to compare the results of the alternative method to the conventional method by impregnation and steaming.

In order to appreciate the differences obtained, an "eco-radar" representation is given in the following figure (Figure 12).

\subsection{Data Analysis}

The process using self-bonding wires has an environmental benefits on 10 of the

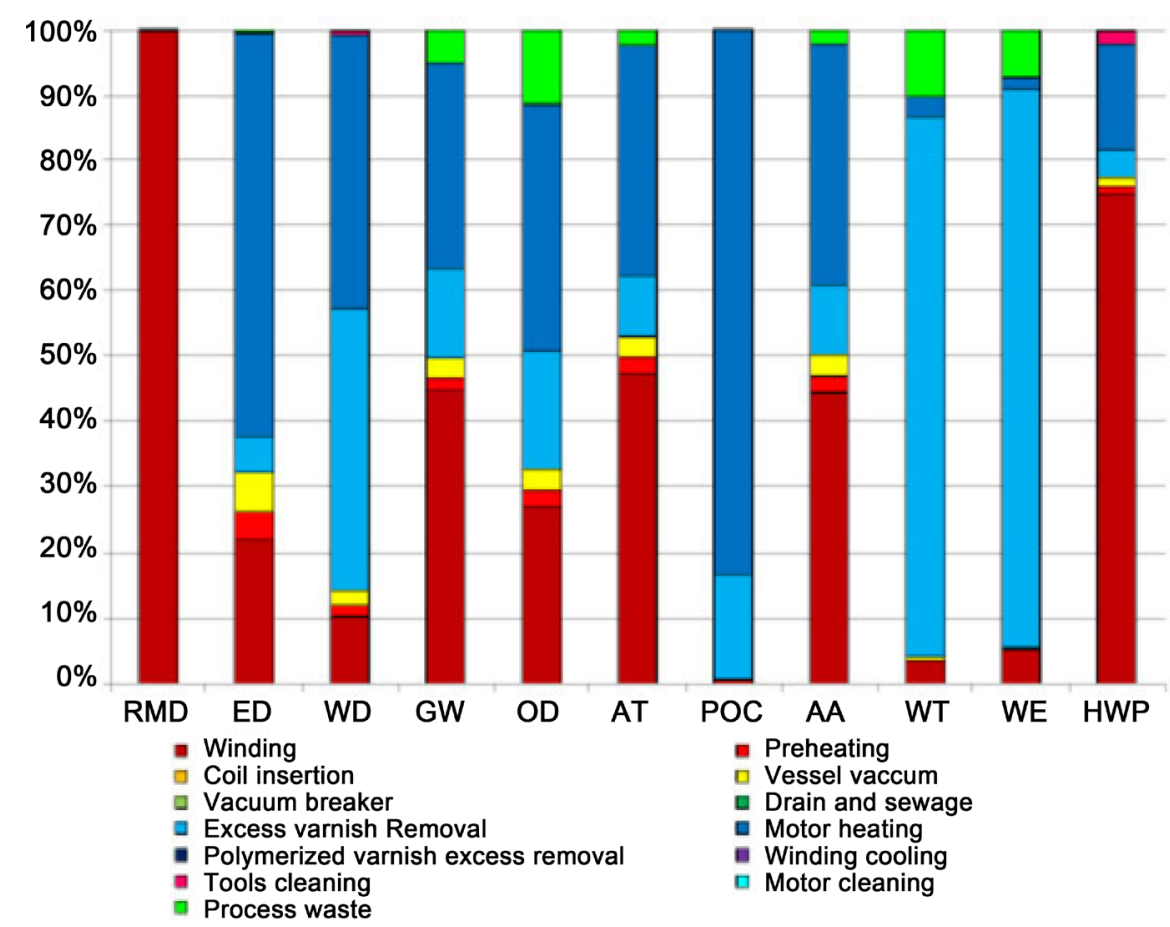

Figure 10. Environmental impact of the conventional impregnation technique. 


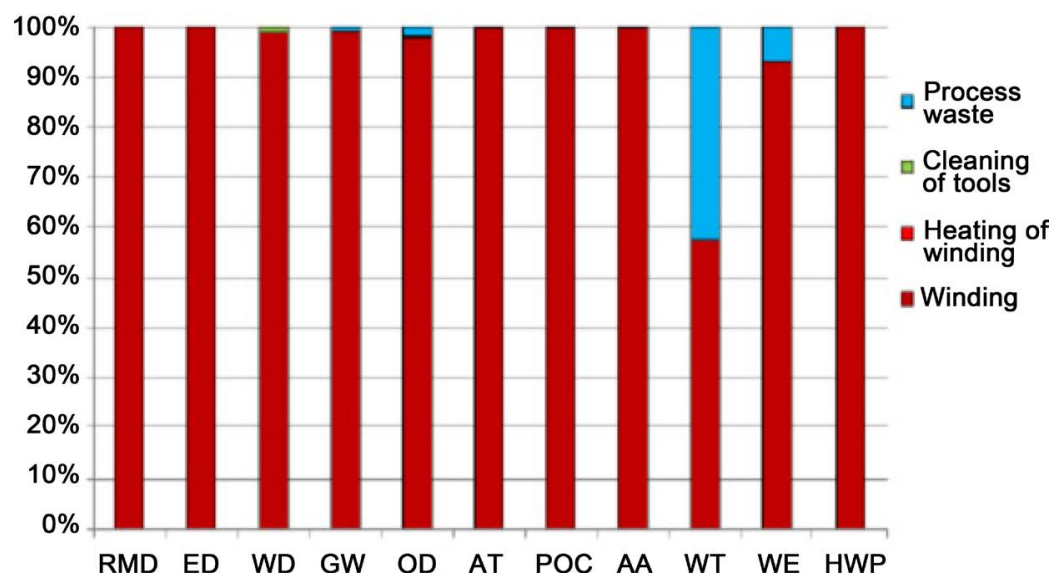

Figure 11. Environmental impact of the self-bonding impregnation technique.

Table 2. $\mathrm{CO}_{2}$ footprints of both impregnating techniques.

\begin{tabular}{cc}
\hline Conventional technique & Self-bonding technique \\
\hline $1.99 \mathrm{~kg}$ & $0.869 \mathrm{~kg}$ \\
\hline
\end{tabular}

Table 3. Environmental impacts of the two impregnating techniques.

\begin{tabular}{cccccc}
\hline Indicator & Unit & \multicolumn{2}{c}{ Classical process } & \multicolumn{2}{c}{ Alternative process } \\
\hline Raw Material Depletion (RMD) & $\mathrm{Y}-1$ & $4.24 \mathrm{E}-14$ & $100 \%$ & $4.24 \mathrm{E}-14$ & $100 \%$ \\
Energy Depletion (ED) & $\mathrm{MJ}$ & 93.3 & $100 \%$ & 19.9 & $21 \%$ \\
Water Depletion (WD) & $\mathrm{dm}^{3}$ & 61.1 & $100 \%$ & 5.07 & $8 \%$ \\
Greenhouse Waste (GW) & $\mathrm{g} \sim \mathrm{CO}^{2}$ & 1990 & $100 \%$ & 869 & $44 \%$ \\
Ozone Depletion (OD) & $\mathrm{g} \sim \mathrm{CFC}-11^{2}$ & $1.34 \mathrm{E}-04$ & $100 \%$ & $3.45 \mathrm{E}-05$ & $26 \%$ \\
Air Toxicity (AT) & $\mathrm{m}^{3}$ & 399,000 & $100 \%$ & 183,000 & $46 \%$ \\
Photochemical Ozone Creation (POC) & $9 \sim \mathrm{C}_{2} \mathrm{H}_{4}$ & 70.5 & $100 \%$ & 0.307 & $<1 \%$ \\
Air Acidification (AA) & $\mathrm{G} \sim \mathrm{H}+$ & 0.314 & $100 \%$ & 0.134 & $43 \%$ \\
Water Toxocity (WT) & $\mathrm{dm}^{3}$ & 3860 & $100 \%$ & 226 & $6 \%$ \\
Water Eutrophisation (WE) & $\mathrm{G} \sim \mathrm{PO}_{4}$ & 1.34 & $100 \%$ & 0.0738 & $6 \%$ \\
Hazardous Waste Production (HWP) & $\mathrm{kg}^{2}$ & 0.0466 & $100 \%$ & 0.0349 & $75 \%$ \\
\hline
\end{tabular}

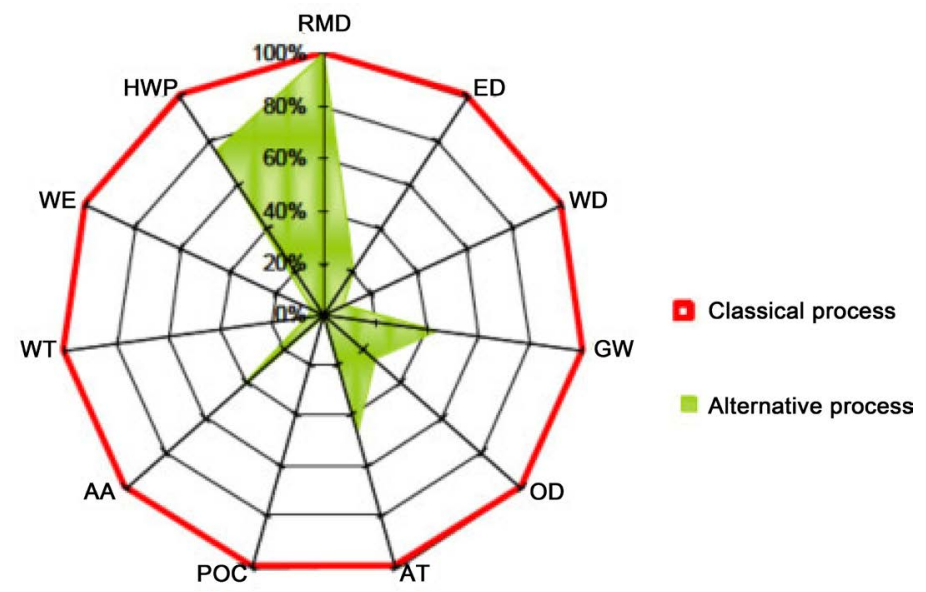

Figure 12. Environmental impacts of the two impregnating techniques (red: conventional techniques, green: self-bonding one). 
11 indicators analyzed. Only the impact on the depletion of natural resources remains the same between the two processes. This is due to the use of the same amount of solder for the two processes. Water consumption, creation of photochemical ozone, water toxicity and eutrophication of water have been reduced by over $92 \%$. The power consumption and the ozone layer destruction were reduced by $79 \%$ and $74 \%$ respectively. The greenhouse effect, toxicity of air and atmospheric acidification has been reduced from 54\% to 57\%. Finally, the production of hazardous waste was reduced by $25 \%$.

\section{Conclusion}

With nearly identical dielectric performances and even higher, the windings made with self-bonding wiresrequire for their implementation the use of a less impactful technic on the environment. Indeed, ten of the eleven analyzed indicators were significantly reduced compared to traditional vacuum impregnation technique and then baking. To be truly, a comparative study should be completed by the analysis of the environmental impact of the production of two types of wires (conventional and self-bonding) and impregnating varnishes. These results are highly promising and suggest a bright future for self-bonding wiresfor their use inthe electrical insulation systems of eco-designed low voltage motors.

\section{References}

[1] Boughanmi, W., Manata, J.P. and Roger, D. (2012) Contribution of LCA Approach to the Choice of Rotating Electrical Machines for Environmental Impact Minimization. Proceeding of the XXth International Conference on Electrical Machines, 122-128.

[2] IEC 60034-18-41 Standard (2014) Rotating Electrical Machines-Part 18-41: Partial Discharge Free Electrical Insulation Systems (Type I) used in Rotating Electrical Machines Fed from Voltage Converters-Qualification and Quality Control Tests.

[3] Anton, A. (2009) Enemaled Wires and Primary Insulation. Technique de l'ingénieur, [D2330] in Converters and Rotating Machines.

[4] Weijun, Y., Bultemeier, K., Barta, D. and Floryan, D. (1997) Improved Magnet Wire for Inverter-Fed Motors. Proceeding on Electrical Insulation Conference and Electrical Manufacturing \& Coil Winding Technology Conference, 379-382.

[5] Kikuchi, H., Yukimori, Y. and Itonaga, S. (2002) Inverter Surge Resistant Enameled Wire Based on Nano-Composite Insulating Material. Hitachi Cable Review, 21, 55-62.

[6] Nguyen, M.Q., Malec, D., Mary, D., Werynski, P., Gornicka, B., Therese, L. and Guillot, P. (2010) Silica Nanofilled Varnish Designed for the Electrical Insulation of Low Voltage Inverter-Fed Motors. IEEE Transactions on Electrical Insulation, 17, 1349-1356. https://doi.org/10.1109/TDEI.2010.5595535

[7] NEMA MW 1000 Standard (2015) Magnet Wire.

[8] ASTM D149-97 (2004) Standard Methods of Test for Dielectric Breakdown Voltage and Dielectric Strength of Electrical Insulating Materials at Commercial Power Frequencies.

[9] IEC 60851-3 Standard (2009) Winding Wires-Test methods-Part 3: Mechanical Properties. 